\title{
ANALYSIS ON PERFORMANCE OF THE EMERGENCY NOURISHMENT PROJECT AT WEST BEACH OF BEIDAIHE, CHINA
}

\author{
Yanxiong Yang ${ }^{1}$, Jiabo Zhang ${ }^{1}$, Cuiping Kuang ${ }^{2, *}$, Yu Zhang ${ }^{3}$, Lulu He, ${ }^{2, *}$, Yi Pan ${ }^{2}$ and Shuguang $\mathrm{Liu}^{2}$
}

\begin{abstract}
Beach erosion is prevalent on China's 18,000 km-long coastline, which has been aggravating due to urban development, river-damming and soil and water conservation projects since late 1970s. Beach erosion threatens the health of beaches of bathing places throughout the world. An effective way to defense the beach erosion is beach nourishment. In this paper, the study on an experimental beach nourishment project, which was conducted to provide data and experience for a large-scale project, is presented. Field survey was conducted to study the performance of the project. Before and after the project, 8 monitoring profiles had been kept measuring. The beach profile measurements indicate that after a little retreat the beach got relatively equilibrium, while the berm measurement shown a broadened intertidal zone getting stable eventually. In a word, the filled beach was eroded a little but finally got relatively stable in the survey period.
\end{abstract}

Keywords: beach erosion, emergency nourishment project, shoreline change, Beidaihe

\section{INTRODUCTION}

Beach erosion is a worldwide natural phenomenon, which poses a threat to tourism. Coastal erosion has been a world-wide problem in recent decades. An estimate made by Bird (1985) shows that about $70 \%$ of the worlds sandy beaches are retreating at a rate of $0.5-1.0 \mathrm{~m}$ a year. Loss of sand can be attributed to natural factors such as storms, sea level changes, waves, currents, tides, wind, bathymetry, shoreline geology, sand supply and quality, and sand movement among dunes, beach, and offshore bars (Bird, 1983; NRC, 1990a). Shortages of sediment can also arise from man-made activities including construction of harbors, groins, jetties, and seawalls; shoreline development; dredging of tidal inlets; damming of rivers; and beach nourishment (London et al., 1981; Kana, 1988; NRC, 1990b).In China, since late 1970s, the beach erosion has been aggravating due to urban development, river-damming and soil and water conservation projects etc.

In USA, prior to the 1950s, the general practice was to use hard structures to protect against beach erosion or storm damages. These structures were usually coastal armoring such as seawalls and revetments or sand-trapping structures such as groins. During the 1920s and 30s, private or local community interests protected many areas of the shore using these techniques in a rather ad hoc manner. In certain resort areas, structures had proliferated to such an extent that the protection actually impeded the recreational use of the beaches. Erosion of the sand continued, but the fixed back-beach line remained, resulting in a loss of beach area. The obtrusiveness and cost of these structures led the USACE (U. S. Army Corps of Engineers) in the late 1940s and early 1950s, to move toward a new, more dynamic, method. USACE projects no longer relied solely on hard coastal defense structures as techniques were developed which replicated the protective characteristics of natural beach and dune systems. The resultant use of artificial beaches and stabilized dunes as an engineering approach was an economically viable and more environmentally friendly means for dissipating wave energy and protecting coastal developments. Artificial beaches also had more aesthetic and recreational value than structured shores. Since the 1970s, 90 percent of the Federal appropriation for shore protection has been for beach nourishment (Hillyer, 1996; USACE, 2002). In Europe, over the last decades, there has been a gradual change from hard to soft coastal defense techniques. Periodic artificial nourishment is widely regarded today as an environmentally acceptable method of beach and dune protection and restoration for short-term urgencies (viz. storm-induced erosion) as well as long-term issues (i.e. structural erosion and relative sea-level rise) (Hanson H. et al., 2002).

\section{STUDY AREA}

West Beach in Beidaihe locates in a famous tourist resort in the south of Qinhuangdao, northeast of Dai river, with several famous and scenic bathing places lying on (Fig. 1). It is characterized by

${ }^{1}$ Qinhuangdao Mineral Resource and Hydrogeological Brigade, Hebei Geological Prospecting Bureau, No.221 Yanshan Road, Qinhuangdao, Hebei Province, 066001, China

2 Department of Hydraulic Engineering, College of Civil Engineering, Tongji University, No.1239 Siping Road, Shanghai, 200092, China. * Corresponding authors, Email:cpkuang@tongji.edu.cn and lulu-stin@163.com

${ }^{3}$ School of Resources and Safety Engineering, China University of Mining and Technology, No.11 Xueyuan Road, Beijing 100083, China 
relatively short (about $3.5 \mathrm{~km}$ length) embayed beach bounded on either extremity by headlands; at the southwest end of the beach there is a jetty used to lead the flow of Dai river to Bohai Bay; at the northeast of the beach there is a cape, where there used to be a jetty which was dismantled in 2002 so that it destroyed the hydrodynamic balance of this area. As a result, the erosion of West Beach in Beidaihe became severe, and the hot spots erosion reaches a value of $50 \mathrm{~m}$ in 4 years. In order to meet the using demand of $6^{\text {th }}$ bathing place on West Beach in the next few summers especially 2008's summer, a small-scale emergency project was carried out in May 2008.

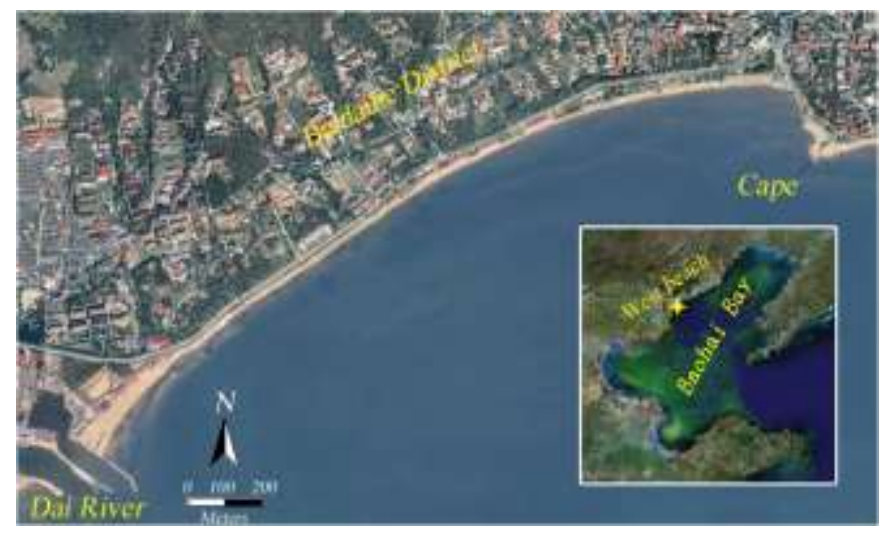

Figure 1. West Beach in Beidaihe, Bohai Bay, China.

Figure 2 gives the nearshore bathymetry around West Beach sea area. It indicates that the slope of the nearshore seabed is very gentle around West Beach. The gradient between $-2 \mathrm{~m}$ to $-5 \mathrm{~m}$ contour arranges from $3.2 \%$ to $3.4 \%$; between $-5 \mathrm{~m}$ to $-10 \mathrm{~m}$ contour is the most gentle, with the gradient arranging from $0.94 \%$ to $0.98 \%$. Nearshore area is the steepest area because of erosion effect, with the gradient arranging from $11.8 \%$ to $17.2 \%$.

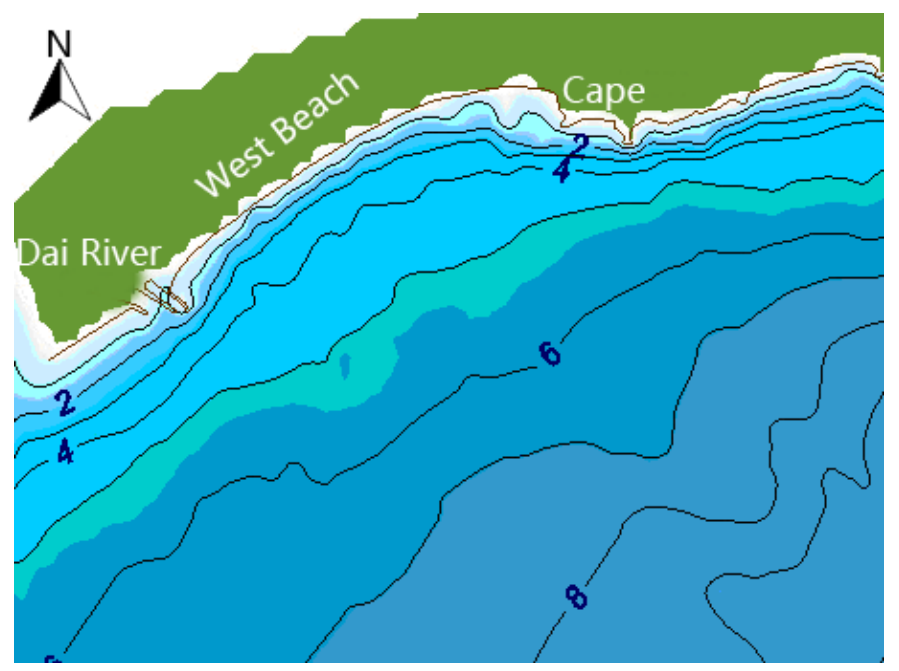

Figure 2. Nearshore bathymetry of engineering area

Wave data was obtained from wave instrument station near the Qinhuangdao port in 2002, 2005 and 2006. Fig. 3 shows the rose diagrams of significant wave height. Among all the waves, the frequency of S direction waves is the highest, accounting for $16.7 \%$; E direction is the second highest, accounting for $10.4 \%$. The waves whose height is smaller than $1 \mathrm{~m}$ account for $96.3 \%$ of all the waves. Among these waves, the frequency of $\mathrm{S}$ direction waves is the highest, accounting for $15.4 \%$; $\mathrm{E}$ direction is the second highest, accounting for $10.0 \%$. The waves whose height ranges from $1.0 \mathrm{~m}$ to 1.5 $\mathrm{m}$ account for $3.1 \%$ of all the waves. Among these waves, these are 4 major wave directions: NE, ENE, 
E and S, accounting for $15.1 \%, 15.9 \%, 11.1 \%$ and $15.1 \%$ separately. The biggest waves come from $\mathrm{N} \sim \mathrm{E}$ direction, accounting for $0.6 \%$ of all the waves. Therefore, $\mathrm{S}$ is the main ordinary wave direction and ENE is the main strong wave direction.

(a)

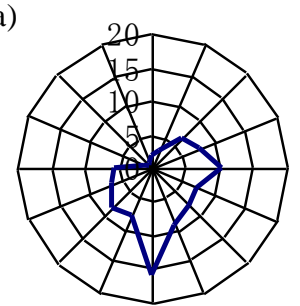

(b)

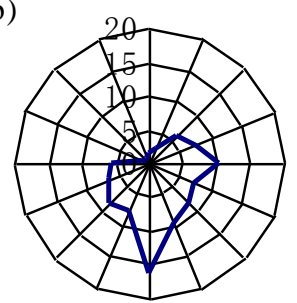

(c)

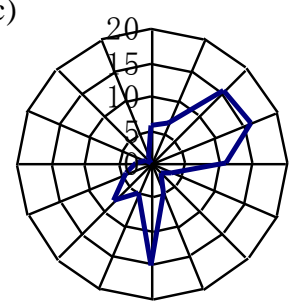

(d)

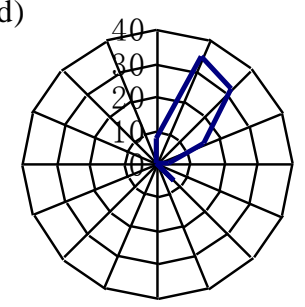

Figure 3. Rose diagrams of wave direction of (a) all waves, (b) the waves $\mathrm{Hs}<1 \mathrm{~m}$, (c) the waves $1 \mathrm{~m}<\mathrm{Hs}<1.5 \mathrm{~m}$, (d) the waves $1.5 \mathrm{~m}<\mathrm{Hs}<2.1 \mathrm{~m}$ (unit: \%).

\section{PROJECT DESCRIPTION}

The emergency beach nourishment project was carried out by Qinhuangdao Mineral Resource and Hydrogeological Brigade, Hebei Geological Prospecting Bureau in May to June 2008, after that the shoreline change has been monitored along 8 cross-sections. In the project, a designing scheme of the beach nourishment with a submerged breakwater is put into practice (Fig. 4). Emergency as its primary character, the project was completed in 42 days (May 2nd 2008 to June 12th 2008). After the completion, the beach is broadened and qualified enough for bathing, and those coastal buildings which were washed directly by the waves are protected by the sand beach (Fig. 5). The feasibility of the project was demonstrated by Kuang et al (2010).

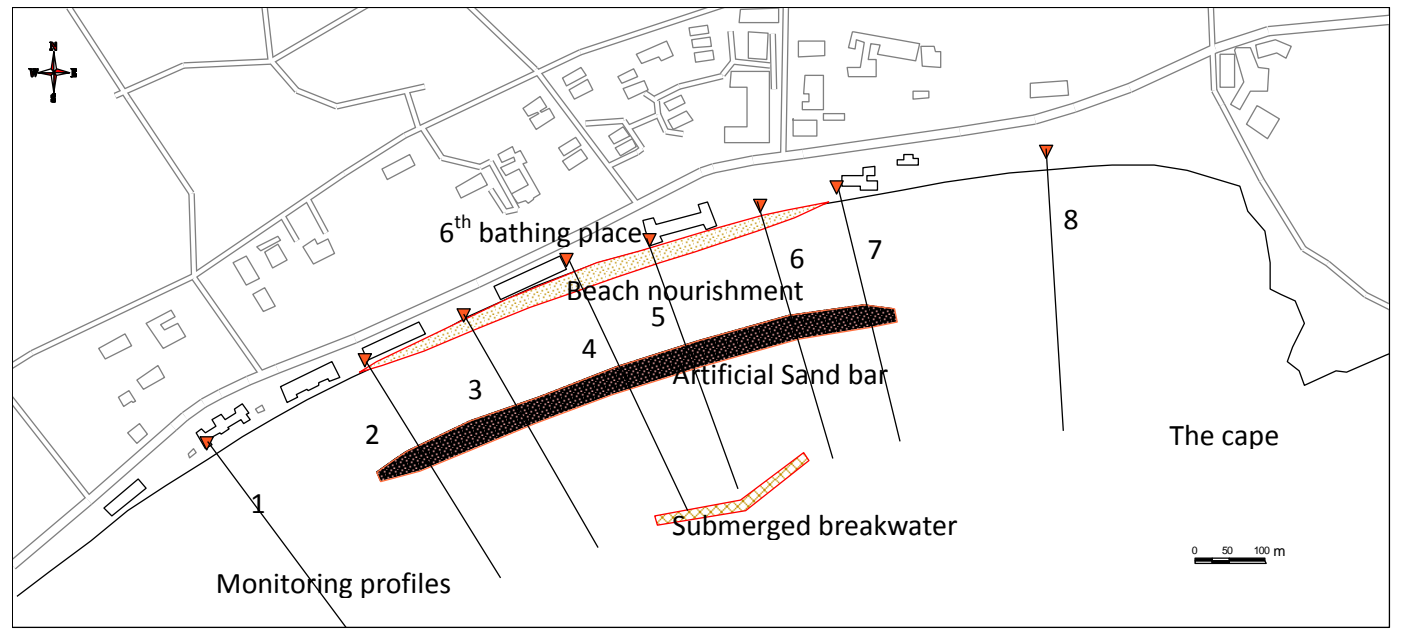

Figure 4. Layout of the emergency project.

The nourishment project was divided into three components, as shown in Fig.4. The first component consisted of the placement of $8.65 \times 10^{4} \mathrm{~m}^{3}$ of sand along the $680-\mathrm{m}$ long beach around the 6th bathing places. The resulting constructed beach nourishment project advanced the shoreline an average of $25 \mathrm{~m}$ (the maximum width is designed to be $30 \mathrm{~m}$ ) seaward along the coastline, with an average berm elevation of about $2 \mathrm{~m}$. The sand placement on beach was constructed during May 2nd to June 12th 2008.

The second component involved the placement of an additional $2.76 \times 10^{4} \mathrm{~m}^{3}$ of sand in the nearshore zone in a water depth of approximately $2 \mathrm{~m}$. This nearshore sand bar was intended to provide a degree of storm protection to the shoreline and to gradually supply the beach surface with sand. The sand bar formed with a crest elevation approximately $1.5 \mathrm{~m}$ below local mean sea level, beginning 
roughly $150 \mathrm{~m}$ from the shoreline, spanning as much as $100 \mathrm{~m}$ in cross-shore width, and extending alongshore over $1400 \mathrm{~m}$ along the center of the beach nourishment project. The nearshore sand bar was constructed between May 16th and June 24th 2008.

The sand placed on the shoreline and in the nearshore sandbar consisted of coarse, medium and fine sands, with a median diameter range from 0.14 to $0.55 \mathrm{~mm}$.

The third component was the construction of a $250 \mathrm{~m}$ long sand-bagged submerged breakwater employing geotextile bags. The breakwater was constructed following the dimension as: crest elevation $=-1.8 \mathrm{~m}$, toe elevation $=-4 \mathrm{~m}$, crest width $=10 \mathrm{~m}$, bottom width $=17.65 \mathrm{~m}$, seaward slope $=1: 3$, landward slope $=1: 1.5$. Total volume of sand used to fill the geotextil bags is $4,400 \mathrm{~m}^{3}$. The construction of geotextil sand-bagged submerged breakwater was accomplished during May 20th to June 8th, 2008.

There're two purposes for the above beach nourishment project: for the short-term purpose is to obtain the primary stabilization of the 6th bathing place in summer 2008 and for the long-term purpose is to provide a typical example for the consecutive study of sandy beaches in Beidaihe District, which means the emergency project will be served as a prototype area and all the recorded data (including the hydrodynamic and morphological data) will be a fundamental base for the beach nourishment project for the whole sandy beaches in Beidaihe District in the future.

Obviously, the beach after the project is now wide enough to bath and relax with the comparison of the beach's appearance before and after the beach nourishment in Fig. 5. And those coastal buildings which were washed directly by the waves are protected by the artificial sandy beach.
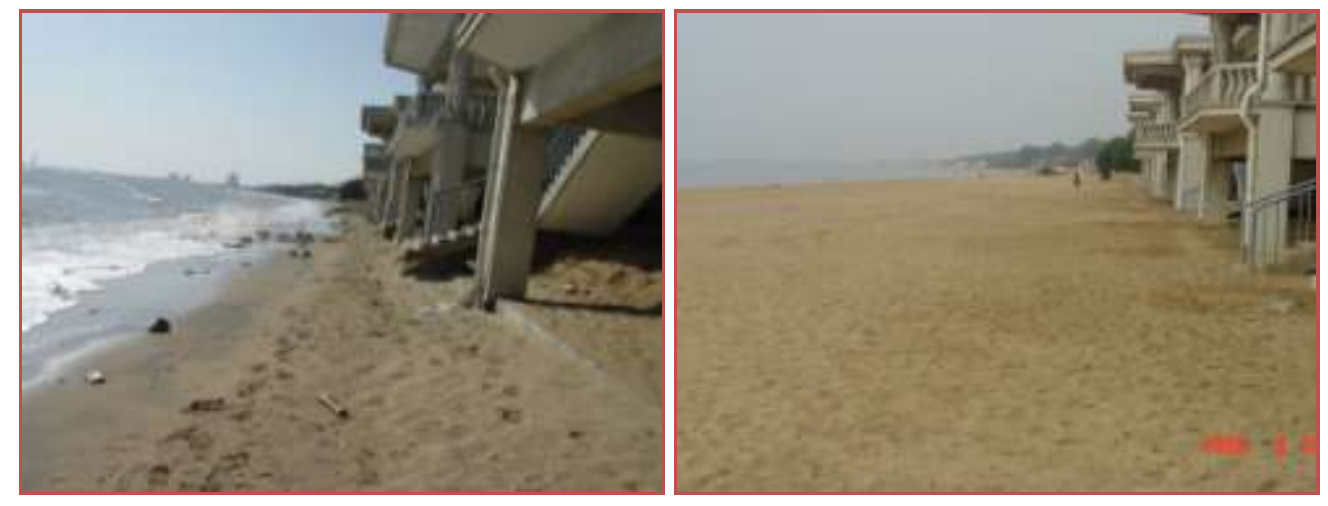

Figure 5. Comparison of the beach's appearances before (left) and after (right) the beach nourishment.

\section{BEACH PROFILES MONITORING}

The monitoring of profiles was conducted by Qinhuangdao Mineral Resource and Hydrogeological Brigade, Hebei Geological Prospecting Bureau. In the project area, along 8 profiles, the beach elevations were measured (Figure 4). In all the monitoring profiles, the distances between two adjacent measure points are less than $5 \mathrm{~m}$. In the area where water depth is less than $1.5 \mathrm{~m}$, the elevations were measured with total stations; in the area where water depth is deeper than $1.5 \mathrm{~m}$, the elevations were measured with sounders. During construction period, the measurements were taken every 10 days; after project, the measurements were taken once a month for first 3 months and then once every three months. After storm tides or big waves happening, additional measurements were taken.

It can be seen in Fig. 6 that erosion occurs after the complete of the beach nourishment project in the middle region of the beach and the maximum retreat distance reaches up to $10 \mathrm{~m}$, resulting in only about $20 \mathrm{~m}$ width beach left in February $11^{\text {th }}, 2009$. However the erosion trend is not so obvious in winter, which could be attributed to the mild wind wave climate in winter in engineering site. While at the two ends of the beach the widths of the beach broad, especially in Profile 1 in the west and Profile 7 in the east. Generally the variation trend of the shoreline is the restoration process of the nourished beach under natural forces. 


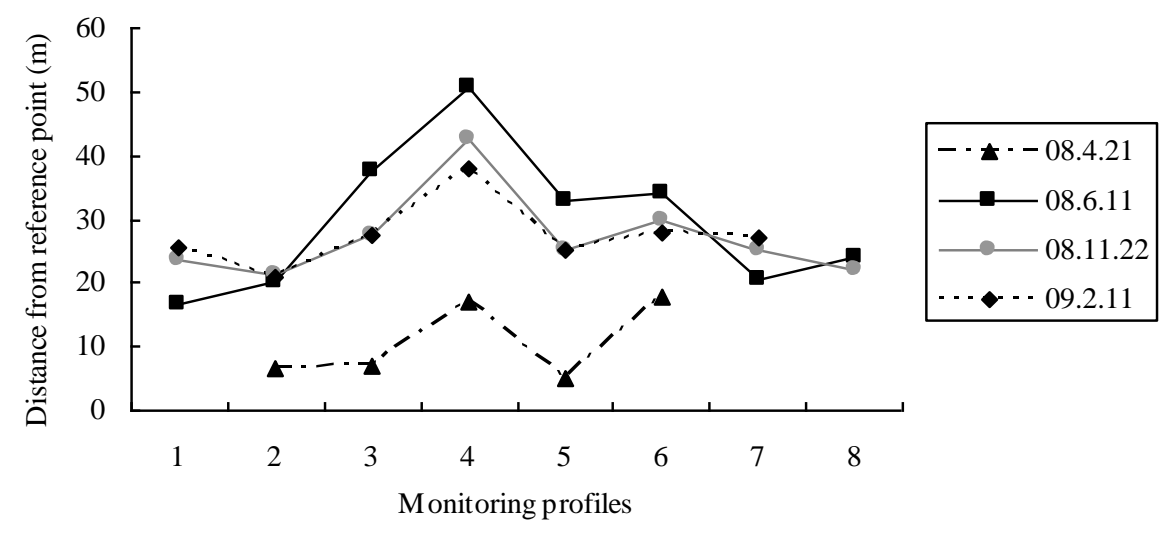

Figure 6. Shoreline positions in the days after the emergency project.

Fig. 7 shows the measurements of the monitoring profiles, including the beach profile before project (data of April 21st, 2008). The average sea level of Beidaihe is $0.03 \mathrm{~m}$ (China's 1985 national height datum). Thus the intersection points of the monitored profiles and $0.03 \mathrm{~m}$ horizontal line indicate the shoreline positions at each monitored profiles.

The measurements show that the shoreline changes along these cross-sections are different: at position of profile 1 and 7, the shoreline went seaward; at the position of profile 3, 4, 5 and 6 , the shoreline kept retreating landward; at the position of profile 2 and 8, the shoreline didn't change obviously. It also can be seen that these changes are little compared with the width of filled beach (the change between April 21st, 2008 and June 11th, 2008). Just as the slow shoreline change mentioned above, beach profiles also have a very slow change in winter (November 22nd, 2008 to March 22nd, 2009).
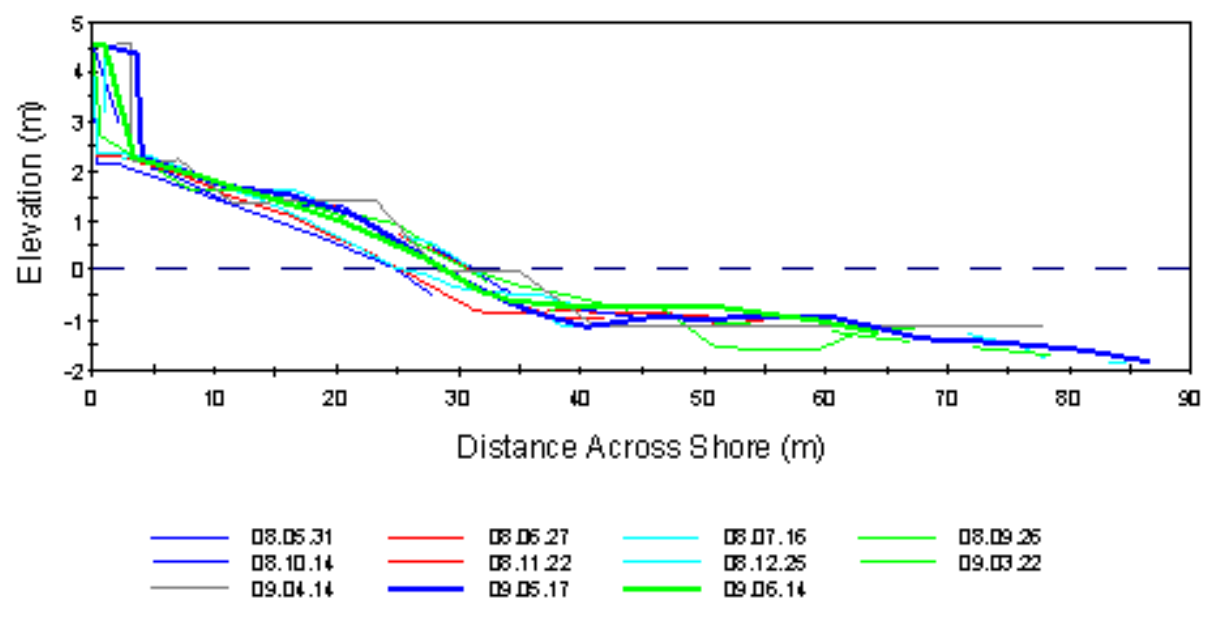

a. Monitoring Profile 1 

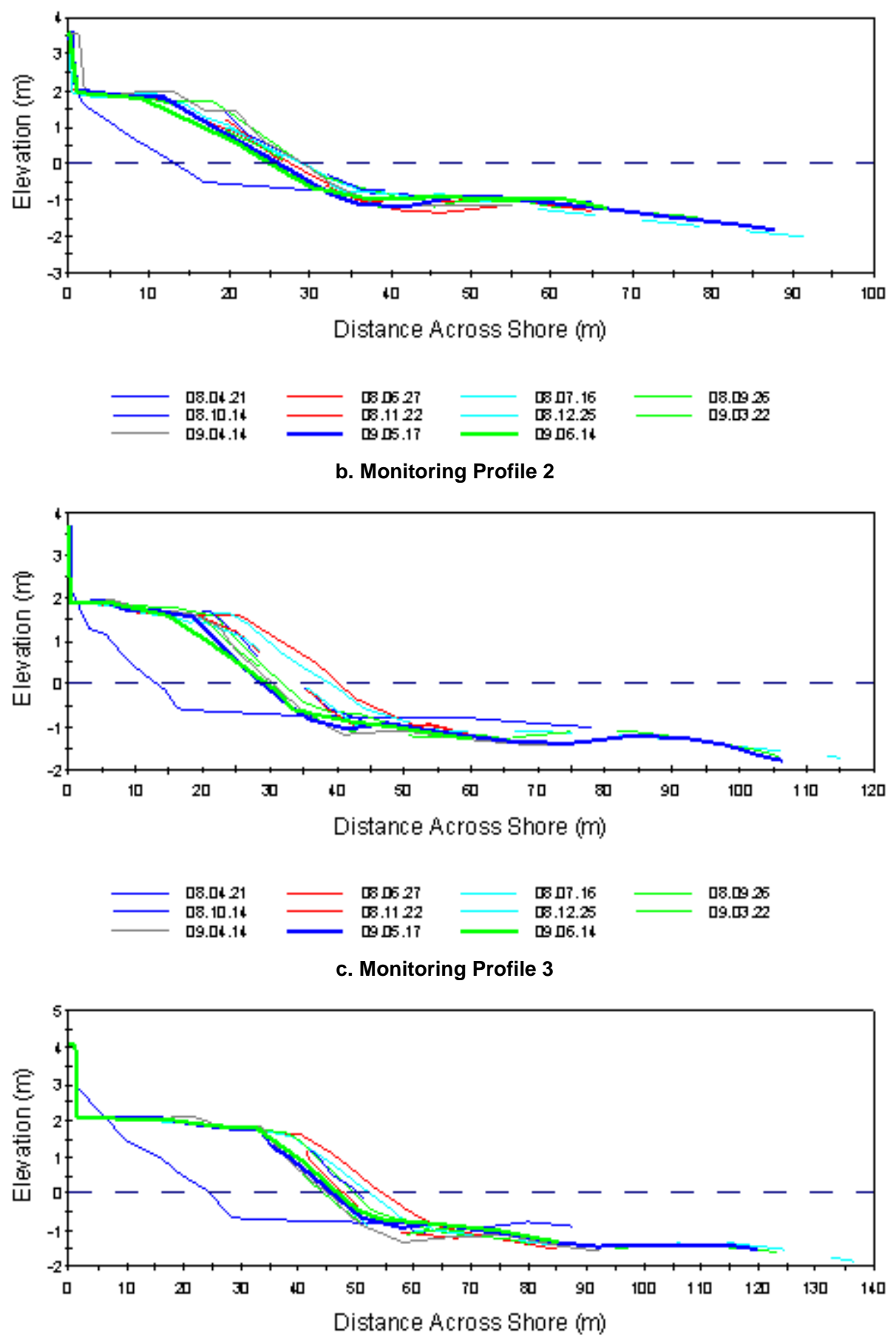

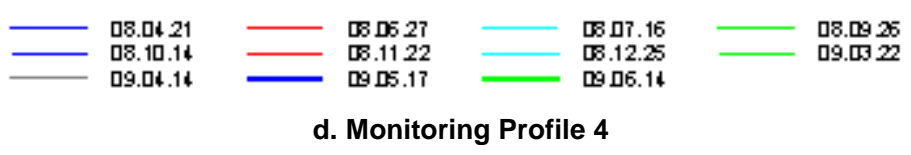



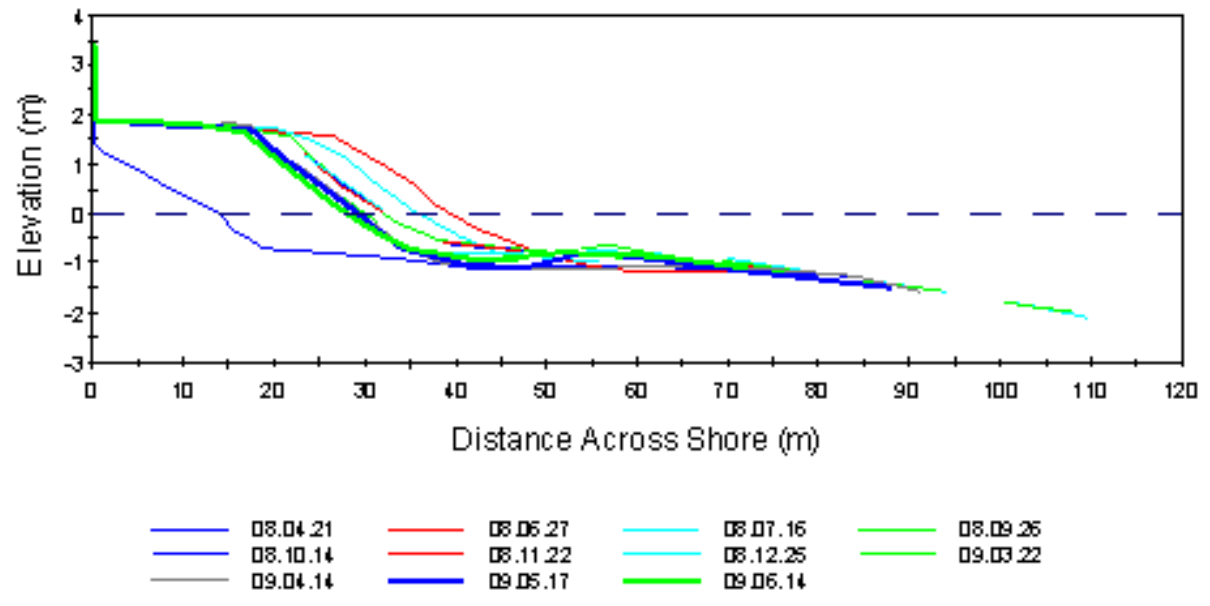

e. Monitoring Profile 5
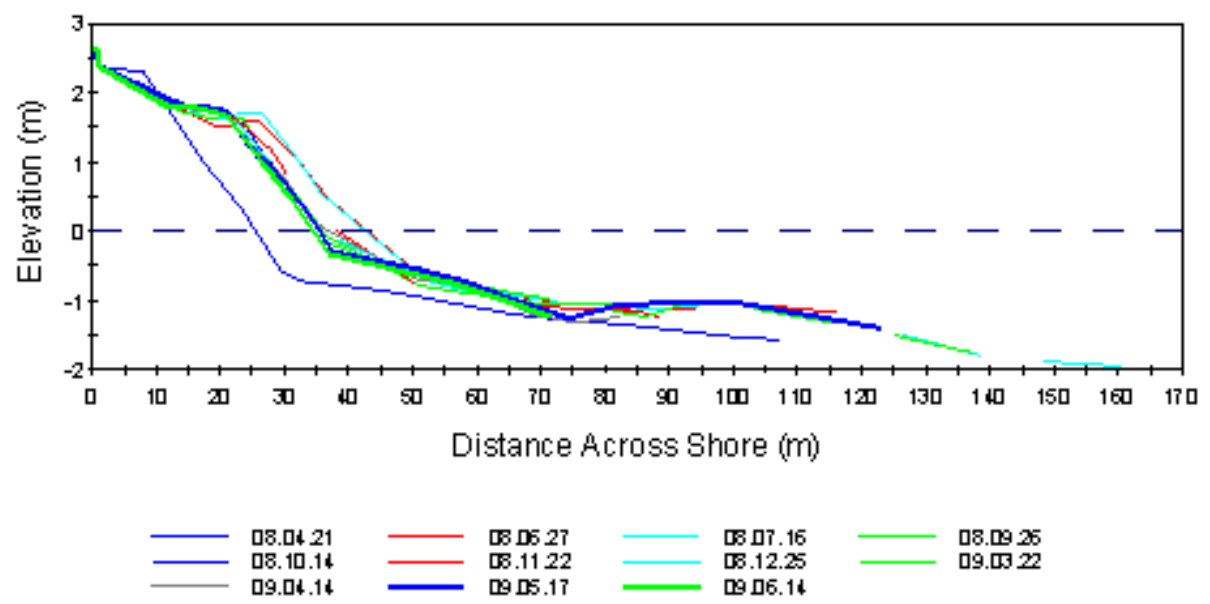

f. Monitoring Profile 6

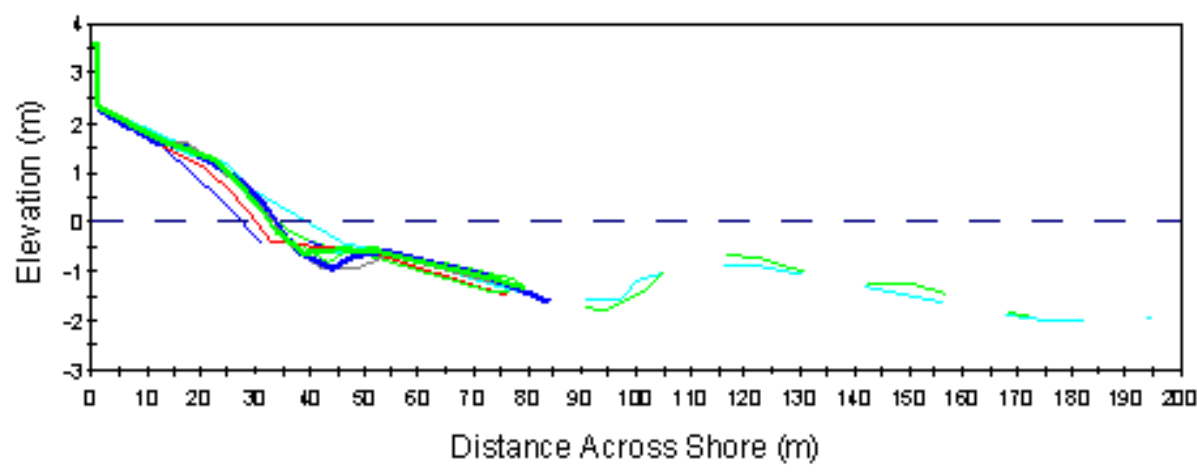

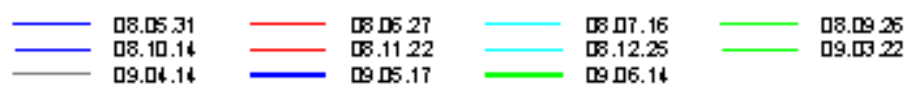

g. Monitoring Profile 7 


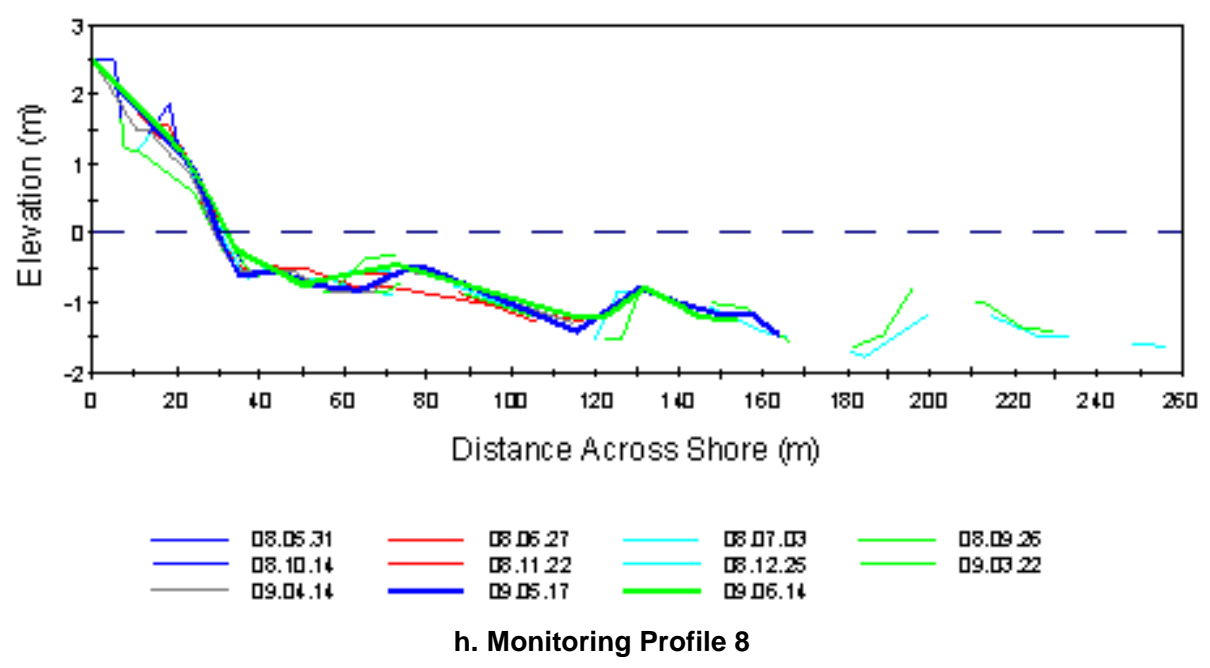

Figure 7. Measurements of the monitoring profiles.

The data of monitoring profiles indicate that the filled beach tends to reach the new equilibrium state. In the longshore direction, the filled beach extruded out of the shoreline like a salient of the seashore and to some degree acts as a groin. The salient was leveled in a natural process. In this process, the sand that swept away from the salient deposit near the filled beach and made adjacent seashore accretion. In the cross-shore direction, the filled beach profiles tend to reach a new equilibrium state with the quick retreat of berm and presence of mild slope and broadened intertidal zone.

In Figure 8, the depth sounder HD30 was used to monitor the data below the mean sea level, which shows the change of artificial sandbar in monitoring profile 3 and profile 5 . The artificial sandbar primarily keeps its original location and seems to reach an equilibrium state, which can protect the filled sand beach as another barrier besides the submerged breakwater. The factors affecting the movement of sandbar like local hydrodynamics and critical diameter of sand should be addressed in the future, to assess this kind of natural method for beach nourishment.
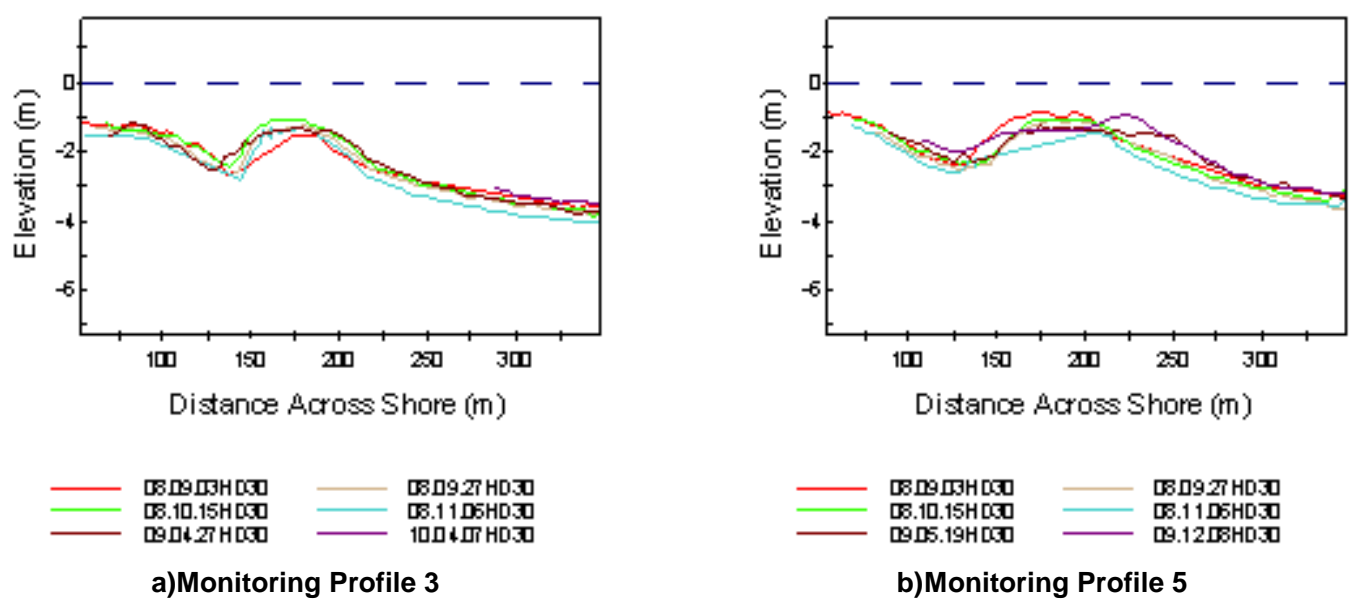

b)Monitoring Profile 5

Figure 8. Measurements of the artificial sandbar.

The measured berm lines and berm toe lines before and after project are shown in figure 9 and figure 10. Figure 9 indicates that the berm kept retreating after the project, with the biggest retreat in 10 m. From Nov.13th, 2008 to Apr. 14 ${ }^{\text {th }}, 2009$, the berm line didn't change much, which indicates that the berm may get relatively equilibrium. Figure 10 indicates that the berm toe line didn't have obvious change after the project. In a word, after the project, the berm retreated to an equilibrium position but 
the bern toe didn't change obviously, as a result the intertidal zone was broadened and it reached a stable state.

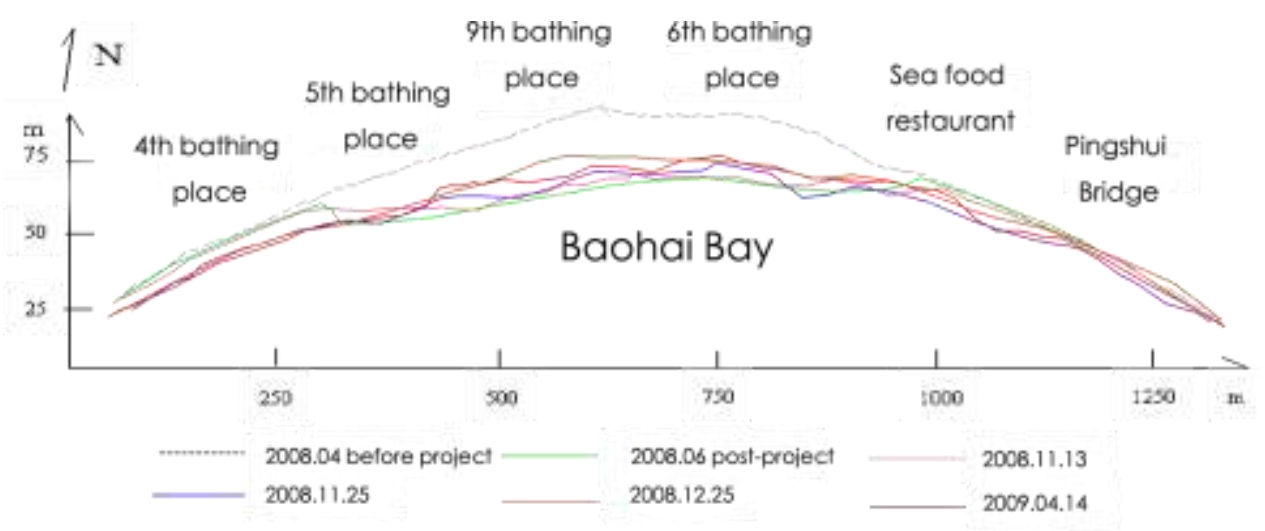

Figure 9. Measurements of berm line before and after project

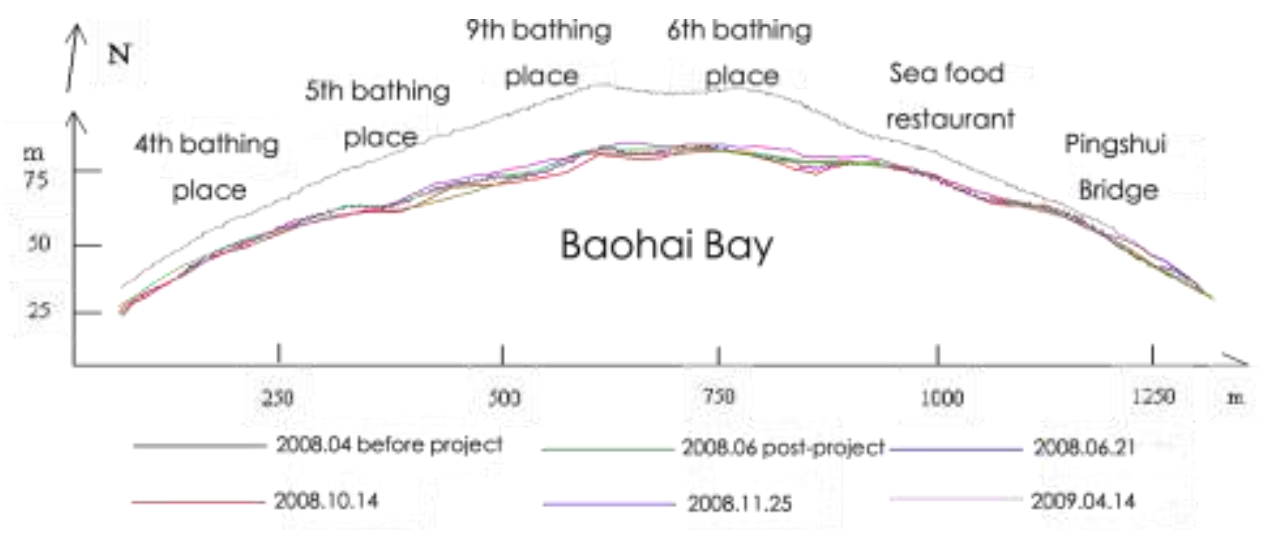

Figure 10. Measurements of berm toe line before and after project

\section{CONCLUSION REMARKS}

This paper details an emergency beach nourishment project and field monitor measurement in Beidaihe, China. After the project, the function of the bathing places got recovered, and the bathing places can provide regular service in summer 2008. The profile monitoring reveals that the middle part of the filled beach keeps eroding while both ends of the beach broaden a little, but the change is small compared with the width of filled beach. The measurement of berm line and berm toe line indicates that after the project, the berm retreated to an equilibrium position but the berm toe didn't change obviously, as a result the intertidal zone was broadened and it reached a stable state. These conclusions based on a short-period field survey. More field surveys still need to be done to study the long-term performance of the project.

\section{ACKNOWLEDGMENTS}

This research is financially supported by funds from the Department of Land and Resources of Hebei Province (HEBEIGT2006ZT, HEBEIGT2008-2903) and from State Oceanic Administration (200905008-05), China.

\section{REFERENCES}

Bird, E.C.F. 1983. Factors influencing beach erosion and accretion: a global review, In Sandy Beaches as Ecosystems. A. McLachlan and T. Erasmus (eds.). Junk, The Hague, 757.

Bird, E. C. F. 1985. Coastline Changes: a Global Review, Wiley- Interscience, Chichester. 
Hanson, H., Kraus, N.C. 1989. GENESIS: generalised model for simulating shoreline change: Report 1. Technical reference. Tech. Rep. CERC-89-19, U.S. Army Engineer Waterways Experiment Station, Coastal Engineering Research Centre. MS, Vicksburg.

Hanson, H., Brampton, A., et al. 2002. Beach nourishment projects, practices, and objectives-a European overview, Coastal Engineering, 47, 87-111.

Hillyer, T.M. 1996. Shoreline Protection and Beach Erosion Control Study, Final Report: An Analysis of the U.S. Army Corps of Engineers Shore Protection Program. IWR Report 96-PS-1, Shoreline Protection and Beach Erosion Control Task Force, Water Resources Support Center, Institute for Water Resources, U.S. Army Corps of Engineers, Alexandria, VA (prepared for the Office of Management and Budget, Washington, DC.).

Kana, T.W. 1988. Beach erosion in South Carolina. SC Sea Grant Consortium, Report SCSG-SP-88-1, 55.

Kuang C.P., Pan Y., Zhang Y., Liu S.G., Yang Y.X., Zhang J.B. 2010. Shoreline change modeling on emergency beach nourishment project on West Beach of Beidaihe, China. China Ocean Engineering, 24, 277-289.

London, J.B., J.S. Fisher, G.A. Zarillo, et al., 1981. A study of shore erosion management issues and options in South Carolina. SC Sea Grant Consortium, Report SCSG-81-1, 246.

National Research Council (NRC). 1990a. Managing Coastal Erosion. National Academy Press, Washington, DC, 182.

National Research Council (NRC), 1990b. Decline of the sea turtles: causes and prevention. National Academy Press, Washington, DC, 259.

USACE (U.S. Army Corps of Engineers). 2002. Coastal Engineering Manual. Engineer Manual 11102-1100. U.S. Army Corps of Engineers, Washington, D.C..

USACE (U.S. Army Corps of Engineers). 1984. Shore Protection Manual. Coastal Engineering Research Center, U.S. Army Corps of Engineers, Vicksburg, MS. 